\title{
REFRACTIVENESS OF PHYSA CUBENSIS (PFEIFFER) AND APPLEXA MARMORATA (GUILDING) TO FASCIOLA HEPATICA (L.)1
}

Vigueras and Moreno² reported Physa cubensis (fig. 1), the most common fresh-water snail in Cuba, to be an intermediate host for the liver-fluke, Fasciola hepatica.

$P$. cubensis ${ }^{3}$ is very common in ponds, creeks, drainage canals, and rivers in Puerto Rico. Another physid snail, Aplexa marmorata (fig. 1), is found occasionally by us in association with Lymnaea columella and Lymnaea cubensis, the intermediate snail hosts of $F$. hepatica in Puerto Rico.

It is highly important to know if these two physid snails of Puerto Rico serve as intermediate hosts for $F$. hepatica, if control measures are to be instituted against fascioliasis.

The specimens of $P$. cubensis used in this study came from an egg mass laid by an individual snail; those of $A$. marmorata from egg masses laid by four snails. Both species were collected from a small fresh water pond at the Agricultural Experiment Station, Río Piedras. Identification of both species was based on their description by Richards. ${ }^{4}$

$P$. cubensis was exposed to $F$. hepatica infection as follows: 1,1001 - to 2-day-old snails were introduced in a small $(10.5 \mathrm{~cm}$.) finger-bowl which contained about 1,000 miracidia in $100 \mathrm{ml}$. dechlorinated tap water; 2, 10021 - to 26-day-old snails were put in a small finger-bowl which contained 1,000 miracidia in $200 \mathrm{ml}$. dechlorinated tap water; 3,50 one- to 2-monthold snails were put in a small finger-bowl containing 1,000 miracidia in 400 ml. dechlorinated tap water; and 4, 10 1-day-old, 10 26-day-old, 10 11/2month old $P$. cubensis and 1021 -day-old $L$. cubensis as control were placed in individual wells of a complement-fixation plastic tray, each containing 10 miracidia in dechlorinated tap water. The snails were observed under a

1 Thanks are expressed to 1)r. F. F. Ferguson, U. S. Public Health Service, San Juan, for advice; Dr. J. J). Rivern-Anaya, Agricultural Experiment Station, Mayagüez Campus, University of Puerto Rico, Río Piedras, P. R., for numerous suggestions and assistance; 1). Luis Rivera-Brenes, P. R. Department of Agriculture, for use of a vehicle, and two veterinary inspectors; Mr. Félix Liard, Jr., Puerto Rico Nuclear Center, University of Puerto Rico, for taking the photograph; and 1)r. C.S. Richards, National Institute of Health, Bethesda, Maryland, for confirming identification of the snails.

2 Vigueras, 1. and Moreno. A., "Physa cubensis" (Mollusca), Un Nuevo Hospedero Intermediario de "Fasciola hepatica (Trematoda), Memorias de la Sociedad Cubana de Hisloria Natural "Felipe Poey" 12 (1): 74, 1938.

3 Van Der Schalie, H., The land and fresh-water mollusks of Puerto Rico, Mus. Zool., Univ. Mich. Misc. Publ. No. 70, pp. 99-100, 1948.

- Richards, C. S., Studies ou Puerto Rican Physidae, Public Hllh. Rep., 79 (11): $1,025-29,1964$. 
dissecting microscope for penetration by the miracidia. The exposure lasted for 4 to $4 \frac{1}{2}$ hours at a room temperature of $29^{\circ}$ to $31^{\circ} \mathrm{C}$.

The $P$. cubensis cultures were kept in 12-gallon plastic aquaria, halffilled with rain water and the $L$. cubensis (control) in individual culture baskets as described by de León. ${ }^{5}$ The snails used to observe penetration of the miracidia were eliminated after the observation. A piece of decaying

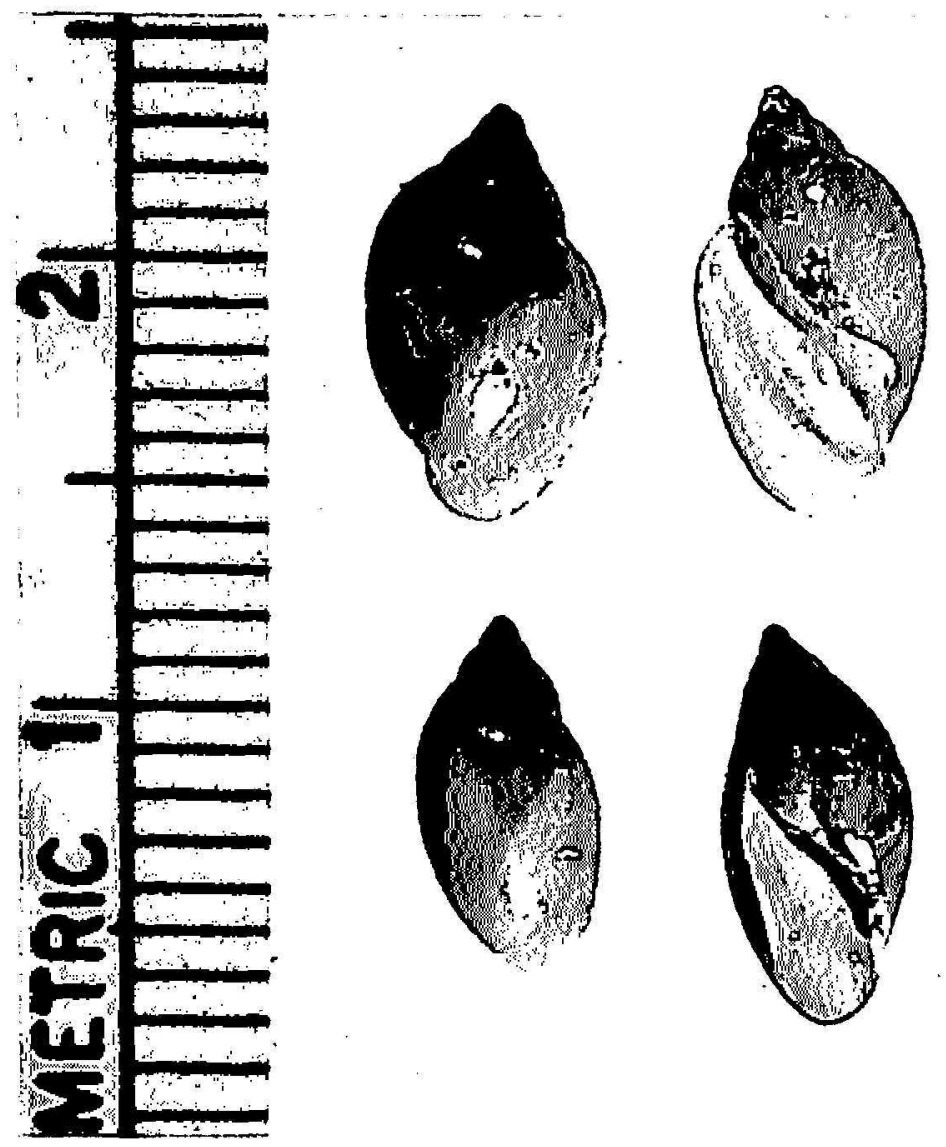

FIG. 1.-Physa rubensis Pfeiffer (above) and A plexa marmoraka (iuilding (below).

malanga leaf (Caladium sp.) was fed once a week. A second trial was conducted following a similar procedure.

Half the snails of each age-group and all the control snails (L. cubensis) in the first and second trials were gently crushed between two glass slides 3 weeks after exposure and their "livers" separated from other tissues and shell fragments. The "livers" then were pressed between a glass slide and a cover slip and examined under the microscope for $F$. hepatica redine. The remaining snails in both trials were eximined similarly 6 weeks after exposure.

s 1)e Jeón, 1). 1)., Life History of Lymnaca columella (Say) and its Experimental infection with Fasciola hepalica (J.), J. .lgr. Unir. P. R. 54 (2) : 297-305. 1970. 
No miracidium penetrated $P$. cubensis after more than 4 hours of exposure; almost all the miracidia penetrated into $L$. cubensis in 15 to 30 minutes. No redia was observed in any of the three age-groups of $P$. cubensis exposed to $F$. hepatica. Many rediae were found in almost all the control snails 3 weeks after exposure. These observations indicate that $P$. cubensis is refractive, apparently, to $F$. hepatica.

$A$. marmorata was exposed to $F$. hepatica infection as follows: 1,40 one- to 2-day-old snails were placed in a small finger-bowl which contained about 250 miracidia in $50 \mathrm{ml}$. dechlorinated tap water; 2, 30 21- to 26-day-old snails were put in a small finger-bowl which contained 500 miracidia in $100 \mathrm{ml}$. dechlorinated tap water; 3, 20 2-month-old snails were held in a finger bowl containing 500 miracidia in $100 \mathrm{ml}$. dechlorinated tap water; and 4, 10 one-day-old and 107 -day-old $L$. cubensis, as control, were placed in individual wells of a complement-fixation plastic tray, each containing five miracidia in dechlorinated tap water. Penetration of the miracidia into the snails was observed under a dissecting microscope. The exposure lasted 4 to $41 / 2$ hours at a room temperature of $29^{\circ}$ to $31^{\circ} \mathrm{C}$.

$A$. marmorata and $L$. cubensis (control) were kept in individual culture baskets. The snails used to observe penetration of the miracidia were eliminated after the observation.

The snails were dissected for rediae using the same method as in $P$. cubensis.

None of the miracidia penetrated $A$. marmorata after more than 4 hours of exposure; almost all the miracidia penetrated into $L$. cubensis in 15 to 30 minutes. No redia was observed in any of the three age-groups of $A$. marmorata exposed to $F$. hepatica. However, many rediae were found in almost all the control snails 3 weeks after exposure. Probably, A. marmorata is also refractive to $F$. hepatica. Furthermore, microscopic examination of the "livers" of 67 A. marmorata, ${ }^{6}$ collected from a swamp in Canóvanas, failed to reveal $F$. hepatica rediae, whereas 9 percent and 25 percent of $L$. columella and $L$. cubensis, respectively, were infected.

Our results are not in accord with Vigueras and Moreno, ${ }^{7}$ who reported that $P$. cubensis is an intermediate host of $F$. hepatica in Cuba. Our negative results are supported by Wright (cited by Taylors) in his statement that all snails serving as intermediate hosts for $F$. hepatica throughout the world belong to a closely-related group belonging to the genus Lymnaea. Moreover, as early as 1883, Thomas (cited by Pantelouris') found $P$.

- Ritchie, L., Chiriboga, J., and de León, D., unpublished data.

7 Vigueras and Moreno, loc. cit.

${ }^{8}$ Taylor, E. L., Fascioliasis and the Liver-fluke, F.A.O. Agricultural Studies No. 64, p. 69, 1964.

Pantelouris, E. M., The Common Liver-fluke, Fasciola hepatica L., 1st ed., Pergamon Press, New York, pp. 20-22, 1965. 
fontinalis to be refractory to $F$. hepatica. We exposed large numbers of $P$. cubensis and $A$. marmorata of an inclusive age spectrum to 10 miracidia each, noting that penetration was not apparent. The rediae observed by Vigueras and Moreno ${ }^{10}$ in natural infections might not have been those of $F$. hepatica. However, it also is possible that the Cuban strain of $P$. cubensis is distinctive in being an intermediate host of at least marginal importance.

D. de Lebn

Department of Animal Husbandry Agricullural Experiment Station

L. Ritchie and $J$. Chiriboga Puerto Rico Nuclear Center University of Puerto Rico

10 Viguerss and Moreno, loc. cit. 